\title{
Survey - Fact or Fiction?
}

The September 1988 MRS BULLETIN included the questionnaire "How Do You Rate Scientific and Technical Programs for Funding Priorities, Blue Ribbon Panels for Effectiveness?" (p. 39). ${ }^{*}$ It was an experiment that, if successful, would validate one route to ascertaining the spectrum of opinions extant within the materials $R \& D$ community on matters of supposed relevance to it.

It is difficult to characterize the survey results in a short and sweet fashion.

On one hand, if the number of responses as a percentage of BULLETIN circulation or MRS membership is a figure of merit, it was a dismal failure. The 60 questionnaires returned represent slightly less than a $1 \%$ response rate and, in the absolute, provide too small a number to lend respectable statistical significance to the data. A $1 \%$ return may be extremely good for junk-mail fund-raising, but it was a disappointing return from an assumed topically ripe affinity group.

It is possible that because the survey was not prominently placed in the BULLETIN, because it received no disproportionate hype in the front matter, and because members were not subsequently peppered with prodding follow-up reminders, it went unnoticed by some who now, reading this, wish they had had the chance to respond.

To all who fit that description, we first apologize for the low profile and now ask that you write us to help us estimate how many of you there are.

On the other hand, we did learn something about surveys from this experience. If the acquisition of many tens of thoughtful responses to topically current issues is a figure of merit, we can describe our experiment as a qualified success. The opinion data we can extract from the responses may best be characterized as believable bias-not only bias of the random Poissonstatistical type but of the systematic nonrepresentative-sampling type to which all surveys are subject.

The most obvious bias in ours is that as

*Credit for the original suggestion and
draft of the survey goes to R.L.
Schwoebel (Sandia National
Laboratories/Albuquerque, New
Mexico), who serves on the MRS
BULLETIN's Technical Editorial Board. many as $99 \%$ answered by, in effect, saying, "We don't fill in and return questionnaires such as this and will leave you to figure out why." Thus the data summarized below reflect the opinions of a select group who are prone to respond to such queries-activists?, the public spirited? those with bones to pick?, or just those who happened to have had the time?-we don't and can't know. An additional caveat is, of course, that the survey questions themselves and their perceived context may have unintentionally allowed or encouraged biased responses. We have no control-group comparisons against which to measure this type of self-biasing propensity.

Column 1 of Table I lists the topical areas in Questions 1-4 of the survey. They are ordered according to the weighted average of answers to Question 1, which asked the respondent to rate each topic according to how important it is that the United States support major funding of a given program in order to maintain and/or improve national and international quality of life and security. Rating is on a scale of 1 (most important) to 5 (least important) with the weighted average tabulated in column 2 of Table I.

Column 3 (Question 3a) gives the percentage of respondents who picked the corresponding topic as one which "might command large funding increases without affecting the funding of other science and technology efforts."

Column 4 (Question $3 b$ ) gives the percentage of respondents who picked the corresponding topic as one which not only satisfied question $3 a$ (i.e., would not affect other funding) but which they believed "should receive significantly increased funding."

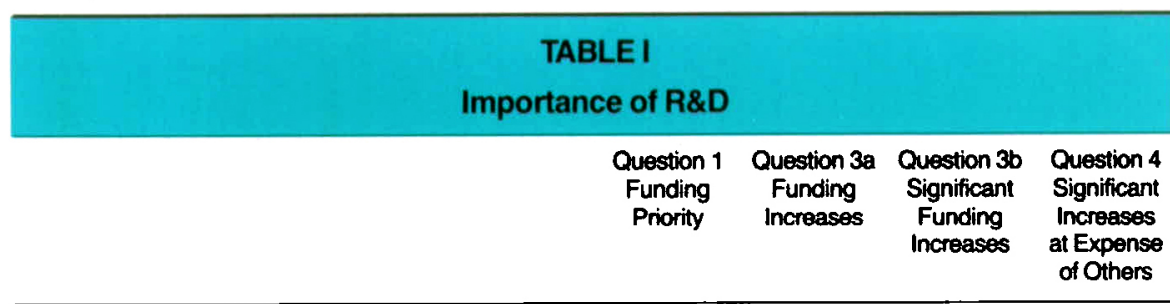

\section{R\&D Area}

Toxic waste

Energy alternatives

Acid rain

Atmospheric ozone depletion

Energy conservation

Semiconductor development

Atmospheric $\mathrm{CO}_{2}$ increase

Augmented university science programs

Solid state sciences

Health care and medicine

Superconductors

Biological initiatives (new)

Agriculture, food \& nutrition

Space sciences

Transportation alternatives

Instrumented space exploration

Technology transfer programs

Manned space flight program

Synchrotron light sources (new)

Space station

Conventional weapons

Nuclear weapons

Strategic defense initiative

Superconducting supercollider

(Aggregate of topics not named here)

(Scale of

1-5)

1.8

1.9

2.1

2.1

2.2

2.3

2.3

2.4

2.4

2.4

2.6

2.8

2.8

2.9

2.9

3.0

3.1

3.3

3.3

3.3

3.6

4.0

4.1

4.1

$1 \%$
30
47
47
40
42
19
35
40
23
12
33
14
14
7
19
14
33
14
12
7
2
9
16

(\%)

55

53

40

36

15

25

30

32

28

25

23

11

17

4

9

9

17

2

4

4

6

2

6

0 
Column 5 (Question 4) gives the percentage of respondents who picked the corresponding topic as one which "should receive significant funding increases at the expense of other efforts in science and technology."

Related to the funding assumptions stated above, Question 2 asked whether "the current and near future federal funding of science and technology is essentially constrained by a 'zero sum' algorithm, i.e., that significant new programs cannot receive large increments on top of existing [total| funding." The breakdown of opinion was:

\begin{tabular}{|l|l|}
\hline YES, there is a zero-sum constraint & $57 \%$ \\
\hline NO, there is no zero-sum constraint & $23 \%$ \\
\hline DON'T KNOW & $20 \%$ \\
\hline
\end{tabular}

Question 5 asked respondents to assign priorities from 1 (highest) to 10 (lowest) to the 10 alternative energy program areas listed in column 1 of Table II "according to their relative importance, and therefore funding, over the next 10 years." The body

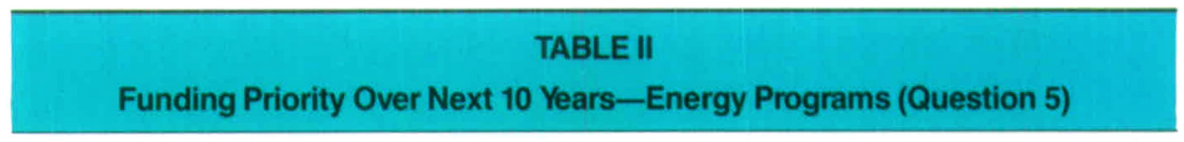

\section{Prionity}

\begin{tabular}{lrrrrrrrrrrr}
$\begin{array}{l}\text { Energy } \\
\text { Alternative }\end{array}$ & $\mathbf{1}$ & $\mathbf{2}$ & $\mathbf{3}$ & $\mathbf{4}$ & $\mathbf{5}$ & $\mathbf{6}$ & $\mathbf{7}$ & $\mathbf{8}$ & $\mathbf{9}$ & $\mathbf{1 0}$ & $\begin{array}{c}\text { Ro } \\
\text { Rating }\end{array}$ \\
Coal utilization & 7 & 3 & 13 & 1 & 9 & 6 & 4 & 5 & 3 & 6 & 2 \\
Conservation & 23 & 10 & 10 & 4 & 4 & 2 & 3 & 1 & 0 & 1 & 1 \\
Geothermal & 1 & 2 & 6 & 7 & 15 & 3 & 5 & 5 & $\mathbf{8}$ & 4 & 3 \\
$\begin{array}{l}\text { Hydroelectric } \\
\text { Natural gas exploration }\end{array}$ & 3 & 2 & 3 & 6 & 11 & 7 & 3 & 4 & 4 & 13 & 3 \\
$\quad$ & & & & & & & & & & & \\
$\quad$ and recovery & 3 & 4 & 9 & 4 & 12 & 4 & 10 & 7 & 3 & 2 & 2 \\
Nuclear power-fission & 5 & 5 & 9 & 9 & 8 & 5 & 2 & 2 & 3 & 7 & 3 \\
Oil exploration and recovery & 10 & 6 & 6 & 3 & 7 & 2 & 3 & 7 & 3 & 7 & 4 \\
Oil shale & 2 & 1 & 4 & 7 & 7 & 9 & 5 & 7 & 5 & 9 & 3 \\
Solar-all forms & 0 & 3 & 3 & 3 & 6 & 8 & 7 & 9 & 7 & 7 & 4 \\
\hline & 22 & 18 & 4 & 5 & 5 & 1 & 2 & 3 & 0 & 1 & 0 \\
\hline
\end{tabular}

of the table displays the frequency with which 59 respondents assigned a given priority to a given area. Some respondents chose to assign the same priority to one topic and/or none to some topics. The former were included in the totals, so check-sums will not always add up to 59 . The latter responses are listed in the "No Rating" column. The paucity of data allows us only to note islands of high or low fre-

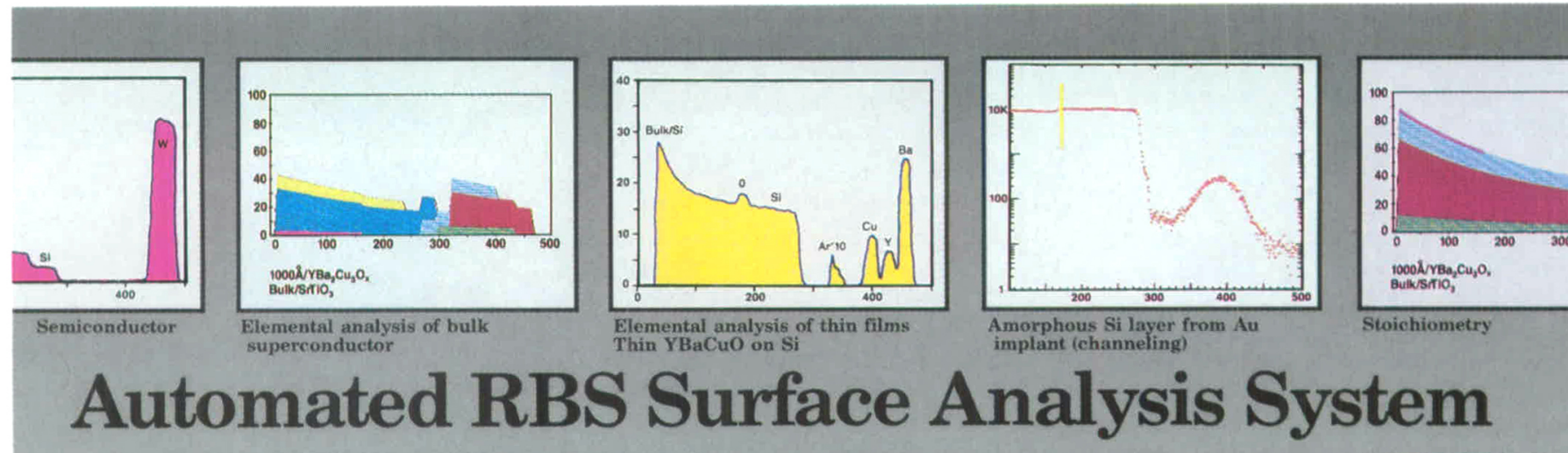

The Model 3S-R10 is an automated Rutherford Backscattering System which combines the versatility of the $1 \mathrm{MV}$ tandem Pelletron ${ }^{\circledR}$ manufactured by National Electrostatics with the fully automated RBS end station manufactured by Charles Evans and Associates.

The computer controlled, energy variable Pelletron accelerator provides helium beams to 3.3 MeV (and protons to 2.2 MeV). The Charles Evans' end station is complete with analysis software and full computer control. With simultaneous data collection and analysis, 100 samples or 100 positions on a single sample can be analyzed without operator intervention. The 3S-R10 is equipped for reliable, unattended operations.

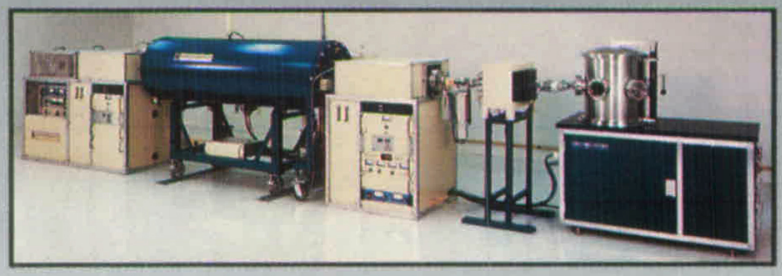

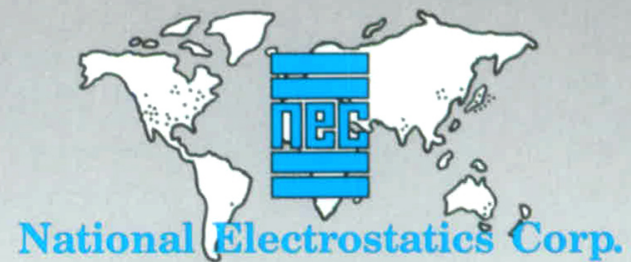

Graber Road, Box 310

Middleton, Wisconsin 53562-0310

Tel. 608/831-7600 • Telex 26-5430 • Fax 608/256-4103 


\section{TABLE III}

Note: Edited for clarity and conciseness.

Comments on Defects/Drawbacks of Blue Ribbon Committees (Question 7)

Process is closed to fresh viewpoints from less established scientists. Committee reports do not receive support from scientific community in general. No public input or consensus process is employed.

These committees are usually representatives of their parochial areas of research and do not give objective views in the national interest. They therefore lack credibility with decision makers.

Nearly all scientists push for increased science funding without regard for the ultimate costs. When was the last time a panel stated that a certain area should receive less or no funding because of needs in nonscience areas taking precedence?

The range of viewpoints tends to be too narrow. The same people or their close associates are frequently appointed.

Need more input from business, political, military, legal and financial communities.

Too much of an "old boys" network. The same people get appointed based on their contacts and past reputation, not on their knowledge and expertise of the particular discipline. Too much politics involved.

\section{Acceptable Alternatives (Question 8)}

Committees should come from APS, MRS, ASM, ACS, etc. Society representatives should form a committee to tackle the issue.

Volunteer!

Ask recognized experts for recommendations. Advertise in journals for volunteers.

Get people interested in science, not politics, by choosing from symposium or session chairs at major scientific meetings.

Solicit applications from scientists who would like to participate in such committees. Get away from the "old boys" network.

Use consortia of hi-tech industries to form panels and choose topics. Use societies like MRS to open up the process to the "grass roots."

Use referenda ... to vote on issues.

Such panels should include nonscientists who are educated in public policy/government.

More effort should be made to include representation from small, as well as large, institutions, states, companies, etc.

...use of national labs to carry out studies.
Examples of Blue Ribbon Committees Missing Mark (Question 10)

As a government contractor, I have personally seen that R\&D funding tends to be motivated to a great extent by "politics," as opposed to objective technical evaluation.

It's not so much a matter of "missing the mark" as of being ignored by those who have a better idea of what's going on; unfortunately, the oft-ignored (except by the press) opinions of these committees are generally the result of a substantial outlay of funds.

Usually the reports seem to end up on bookshelves unread and un-implemented.

Reports don't get much attention in the right quarters. Probably need some "follow-up" procedure, i.e., more pressure on politicians.

Environmental concerns have been largely unaddressed/avoided.

Funding agencies or management do not pay attention.

Usually are in favor of everything.

COSMAT report of early 1970 s-no impact-too big/obtuse-poor publicity. Seitz-Eastmann panel on large facilities-[no] community support. Packard report on national labs-no laboratory mandate to react.

General tendency of government is to ignore suggestions of significant change from current policy: e.g., acid rain, fluorocarbon effects or ozone depletion. Tendency is to ignore warnings until problems reach near-crisis proportions.

The problem is that often such blue ribbon panels are an excuse for inactivity.

Effective implementation is often prevented by political considerations. Technical panels are correct to consider ideal solutions, but should also suggest alternatives that might avoid stupid administrative decisions.

We have had far too many blue ribbon panels. Every time there is a problem, a committee is appointed, it issues a report that promptly gathers dust. The technical community knows what the problems are, they are obvious and at times, so are the solutions. The crux of the matter is the implementation which is often obstructed by bureaucratic infighting and incompetence.

Effective implementation depends on whether those requesting the blue ribbon committee really want to hear what they think or if they simply want a favorable endorsement for political purposes (e.g., the NAS panel recommendations on lasers in SDI were largely ignored by the Reagan Administration because they were not favorable).

An example is the recommendation of the supercollider in a climate of declining resources with no consideration of joint international effort in this area and no clear delineation of real benefits. quency from which general preferences may be inferred.

The remainder of the questionnaire dealt with opinion about so-called "blue ribbon" committees. Question 6 asked whether the current means by which such committees are formed through bodies such as the $\mathrm{Na}$ tional Academies, etc. "is the most appropriate process." The result:

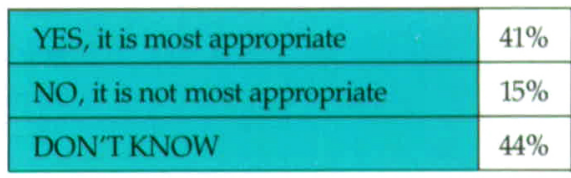

Fourteen respondents answering "no" responded to Question 7, which asked them to identify the drawbacks of the current process. Some responses are provided in Table III. Similarly, Question 8 asked respondents to "suggest acceptable alternative procedures for forming such committees." Twenty-two comments, some of which can also be found in Table III, were received.

Question 9 read, "By and large, have the reports of blue ribbon panels resulted in effective implementation of recommendations?" The answers break down as:

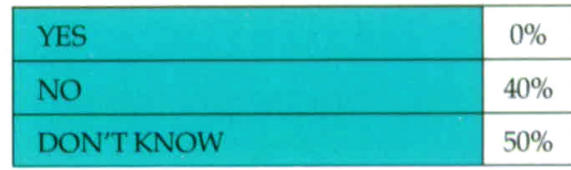

Those answering "no" sent 19 comments in response to Question 10 which asked for "examples of how they may have missed the mark." These too are partly repeated in Table III.

With all of the disclaimers mentioned at the outset of this report, readers are left to draw their own conclusions regarding whether any of the apparent trends in these data and comments ring true or are at least consistent with their own individual sense of mainstream opinion.

We leave this survey behind with one last observation. Although 60 respondents is a small number for a survey and most certainly provides a skewed view of community opinion at large, 60 is normally several times greater than the typical number of blue ribbon panel members for whom the selection process risks the same opportunity for systematic nonrepresentative-sampling error.

E.N. KAUFMANN 

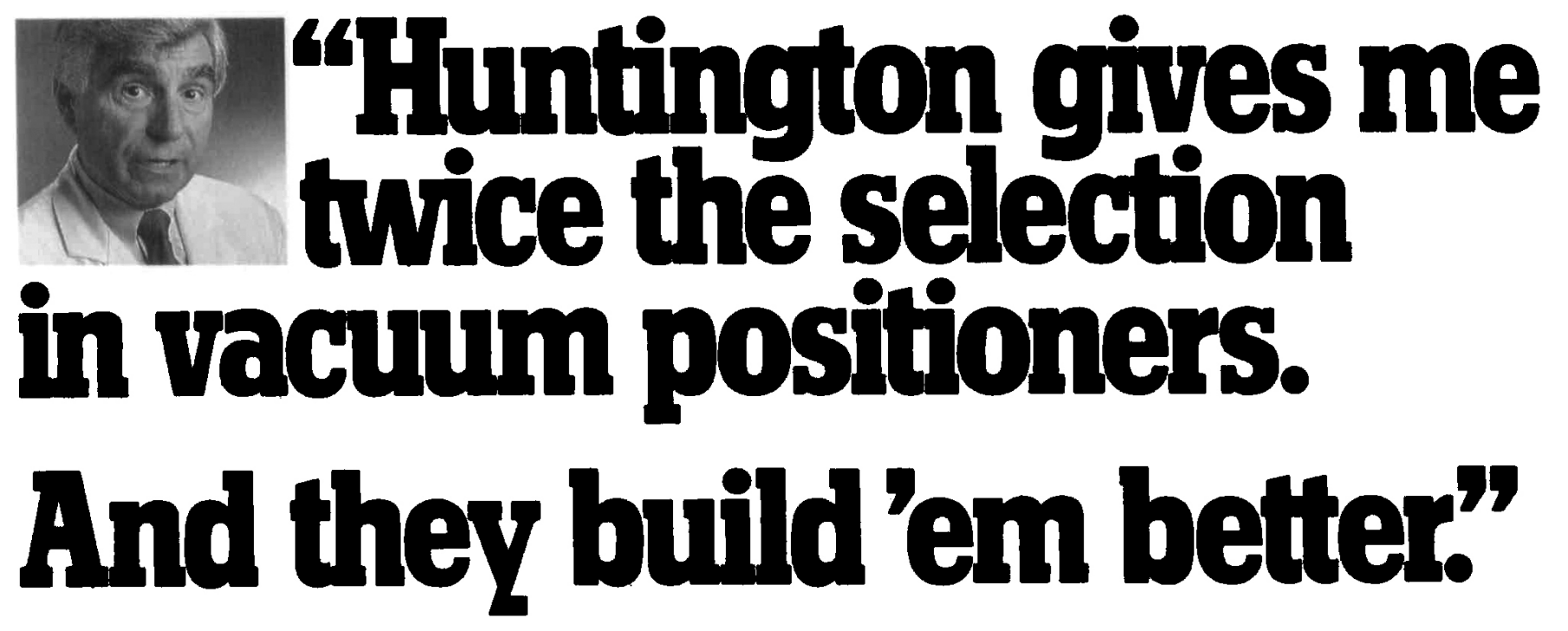

\section{Get exactly what you need.}

In vacuum positioners and feedthroughs, Huntington gives you more than twice the selection...

Linear, rotary, angular and $X-Y-Z$ precision manipulators. Coaxial and multimotion, too. Motorized, manual, pneumatic, you name it. With accessories for gripping, holding, transferring, even heating and cooling samples in vacuum. Combine parts and get even greater variety.

Whether you need bellows-sealed, magneticallycoupled, differentially pumped or any combination. From rough to micron-precise motion control, you'll get exactly what you want. In a range of pricing, to meet your budget.

\section{Faster response. Even on specials.}

Huntington keeps a lot more product in stock. Which is why more than $90 \%$ of their orders ship within 72 hours.

If you need a special modification or combination, or something entirely new, just say the word. Huntington has the engineering staff and talent to make it happen, fast.

\section{Innovative design. Better construction.}

It's not surprising that Huntington has the most patents...

Like its new Polar Coordinate Manipulator, which lets you move in a straight line instead of X-Y zig-zags.

Like rotary feedthroughs that deliver higher torque in smaller envelopes by eliminating old bent-shaft designs.

Like Huntington's unique ball-bearing Acu-Port which turns effortlessly, even when supporting heavy devices.

And no one builds positioners like Huntington: Maximum-life bellows design. No plastic parts, because

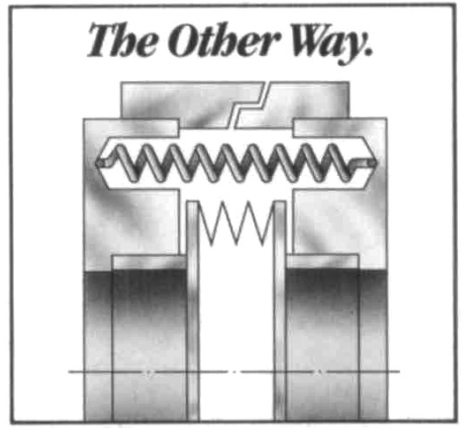

Other port-aligners are beld together with springs. Friction makes them bard to turn. Heavy feedtbroughs pull them apart.

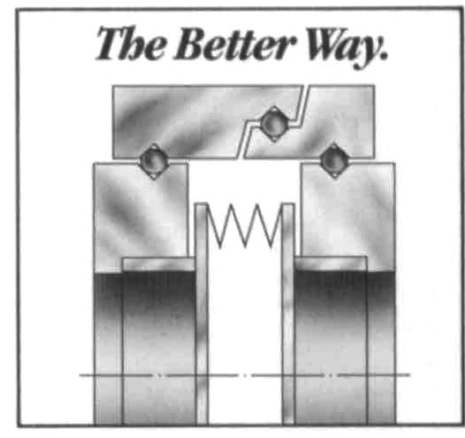

Huntington's patented Acu-Port uitb interlocking ball bearings turns smootbly and easily, even when supporting beaty devices. most Huntington positioners are bakeable to $450^{\circ} \mathrm{C}$. And special Summa Process treatment to make Huntington's stainless steel chemically cleaner and physically smoother.

\section{Get your free Huntington catalog, now.}

The full spectrum of better-built Huntington vacuum components, including positioners, is detailed in the new catalog...

For your free copy, just call or write: Huntington Laboratories, 1040 LAvenida, Mountain View, CA94043. (800) 227-8059 or (415) 964-3323.

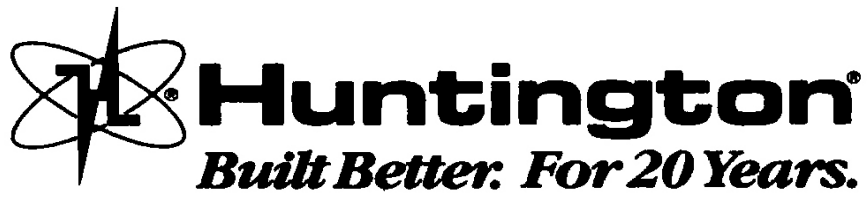

